\title{
Decision Support to Identification of Road Infrastructure Segments With Poor Conditions
}

\author{
Nikša Jajac \\ Faculty of Civil Engineering, Architecture and Geodesy, University of Split, Matice hrvatske 15, \\ 21214 Split, Croatia, niksa.jajac@gradst.hr
}

\begin{abstract}
Planning of maintenance activities (an integral approach) on ever growing system such as urban road infrastructure requires decision makers to take into account large number of different data and usually conflicted criteria, derived from several aspects of analysed problem. This systematic approach to planning is based on the main three steps: identification of alternatives, their validation and selection for inclusion into a maintenance plan. Most of authors are dealing with the last two steps however, focus of this research is on the first step. This step is a critical phase of planning because it is important to identify road infrastructure segments that need to be improved. Meaning, those with poor condition. The condition of a segment must be expressed as simple as possible (by unique Condition Assessment Value) and by usage of few but most relevant criteria (such as level of service, safety, time period passed form the last renovation and stability). Another important issue is provision of relevant, relatively quick and consistent expert assessment of segment condition according to above mentioned criteria and for large number of segment. To insure such assessment with high quality of segments identification this paper propose an decision support concept/expert system based on combination of trained and tested Artificial Neural Networks (ANN) and Simple Additive Weighting (SAW) method. The concept is validated on urban road infrastructure of city centre of Split, Croatia and it proved to be useful for determining a set of road infrastructure segments where maintenance activities should be undertaken.
\end{abstract}

Keywords: Decision Support Concept, Road Infrastructure Segments, Planning, Artificial Neural Networks.

\section{Introduction}

In the field of urban road infrastructure systems, planning process of maintenance activities is highly complex and ill structured problem. This complexity is defined by several factors: lots of stakeholders with different opinions, huge amount of information quantities, multidisciplinary character of the problem, conflicts among goals and criteria, budget restrictions, etc. These factors indicate that the decision-making to maintaining activities of the road infrastructure planning are burdened with complex and socially sensitive problems, especially for the long-term planning. For that reason, long-term planning tasks should be supported by decision making tools such are multicriteria methods that can contribute to a more efficient realization of the tasks. In order to manage such complexity, a decision support approach is proposed, aimed at improving decision making to planning of maintain activates at the road infrastructure system. This concept represents a multicriteria decision-making approach, and is based on multicriteria analysis. Three main steps are crucial for a realization of planning: identification of alternatives, their validation and selection for inclusion into a maintenance plan. In this research, focus is given to the first step where road infrastructure 
segments are identified and need to be improved because of their poor condition. These conditions are express by Condition Assessment Value (CAV), using few the most relevant criteria (such as level of service, safety and time period passed form the last renovation, etc.).

Expert assessment of segments conditions according to defined criteria are given and to achieve the most precise assessment this paper propose an decision support concept and expert system based on combination of trained and tested Artificial Neural Networks (ANN) and Simple Additive Weighting (SAW) method. There are many studies dealing with possibilities of generating decision support tools for maintaining road infrastructure segments. Zavdskas, Liias and Turskis (2008) gave a review of international and national practices in investment decision support tools in bridges and road quality management. He, Song and Chaudhry (2013) in their paper, explored the integration problem of service-oriented system and intelligence technology through the use of a group decision support system, applied on transportation management. Petty and Mahoney (2008) gave enhancements and refinements associated with winter maintenance decisions that the United States Federal Highway Administration initiated in a project aimed at developing a winter road Maintenance Decision Support System (MDSS).

The goals of the MDSS project were to construct a functional prototype MDSS that can provide objective guidance to winter road maintenance decision makers concerning the appropriate treatment strategies These strategies are used to control roadway snow and ice during adverse winter weather events, and develop a prototype that will also serve as a catalyst for additional research and development by the private sector. Dunkel et al. (2011) proposed a reference architecture for event-driven traffic management systems, which enables the analysis and processing of complex event streams in real-time and is therefore we l-suited for decision
support in sensor-based traffic control systems. Zhou et al. (2010) presented a research effort
undertaken to explord the applicabitity of data mining and knowledge discovery (DMKD) in
combination with Geographic Information. System (GIS) technology to payement management
to better decide maintenance strategies, set rehabilitation priorities, and male investment decisions. Bielli (1992) presented a decision support system to urban-traffic management to

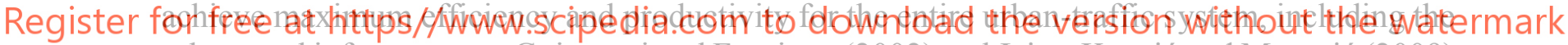
urban road infrastructure. Guisseppi and Forgione (2002) and Jajac, Knezić and Marović (2009) in their papers gave a cost and benefit aspect of potential infrastructure investments, showing that several decision-support models can be generated. Quintero, Konaré and Pierre (2005) described an improved decision support system named Intelligent Decision Support System that coordinates management of several urban infrastructure systems, such as the sewage and waterworks. Proposed Intelligent Decision Support System was a solution for the future urban infrastructure management. Similar approaches were given by Pomerol, Roy and RosenthalSabroux (1996), Turban and Aronson (1995) and Leclerc et al. (2001). Sayers, Jessop and Hills (2003) used SAW method (Hwang and Yoon, 1981) to present a multicriteria evaluation of transport infrastructure for ranking transport investments. These investments aim was to improve infrastructure in small towns, analysing three solutions: minimum interventions on the existing network, upgrading the existing route, and building a bypass. A simplified transport project ranking methodology with an integrated multicriteria decision making process that prioritizes transport projects in cases when multiple stakeholders present various different opinions was given by Shelton and Medina (2010) and Jajac, Marovic and Baucic (2014). Jajac (2010) made a research on the development and maintenance of urban road infrastructure by implementing and using multicriteria analysis and ANN at strategic, tactical and operating 
decision making levels, in urban areas. To improve a decision making process in such complex circumstances, it is important to develop new tools aimed at raising the level of transparency and objectivity in the solution-selection process (Jajac, 2010). This research is focused on decision support concept to maintenance activities panning of improving road infrastructure segments in urban areas. It is based on the multicriteria methods AHP and SAW, and expert systems, using ANN, to support project management. The concept is validated on the urban road infrastructure of the city centre of Split, Croatia, and proved to be useful for determining a set of road infrastructure segments where maintenance activities should be undertaken.

\section{Decision Support to Improve Maintenance Planning of Road Infrastructure Segments}

Using architecture of the DSS for urban-infrastructure management (Jajac, 2010), a decision support to planning of maintenance activates improvement of road infrastructure segments is developed. The model for improving urban road infrastructure segments maintenance planning is proposed in Figure 1. The process of decision-making starts at the strategic and tactical levels, where with the case study is determined and stakeholders are selected. The main characteristics of each segment of infrastructure are collected and stored in database, they are accessible for entering periodically new inputs at the operational level during the continuous maintenance process. These main characteristics of segments are important for defining criteria and their weights. Firstly, stakeholder are selected and gathered together through subjective assessment

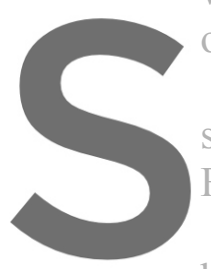
of their influence and legitima Local government several administrative Finance, Office for Phys Experts - civil engineering,
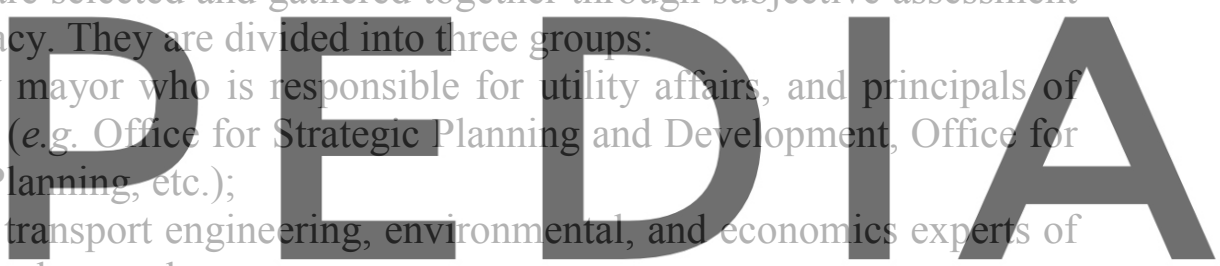
both academic and practical backgrounds;

Register for Urers - the representatives of city districts or similar city formations goal analysis is given in the form of hierarchical structure of goals and criteria. The criteria are defined by local government and experts group, while criteria weights are determined by all stakeholder groups. Using the AHP method (Saaty, 1982) and interviewing all stakeholders, weights can easily be assigned through a group decision-making process. The decision-making process of each stakeholder group must be repeated until consistency of each group' criteria weights determination is achieved. Furthermore, having determined the hierarchy of goals and stakeholder groups, three scenarios are developed, while the final (fourth) scenario is determined as the compromise opinion of all groups. Values of the compromise opinion are introduced as weights for the SAW method, which is used to set priority of selected road segments according to their improvement requirements. After the goal hierarchy is defined, all segments are analyzed, and those with conditions that need to be improved are identified using ANN. This way the condition assessment for all segments is provided within the study area. Only those segments with the condition assessed as poor, unsuitable and worn-out are selected for further analysis and priority-setting. Moreover, the segments are then ranked according to defined criteria. The local-government representatives, as strategic decision-makers, assisted to the group of experts in selecting the most convenient solution based on the present policies and 
multicriteria analysis. The selected solution establishes a strategic plan of the road infrastructure segments conditions improvement. The proposed concept was tested on the road infrastructure segments maintenance planning in the city of Split, Croatia.

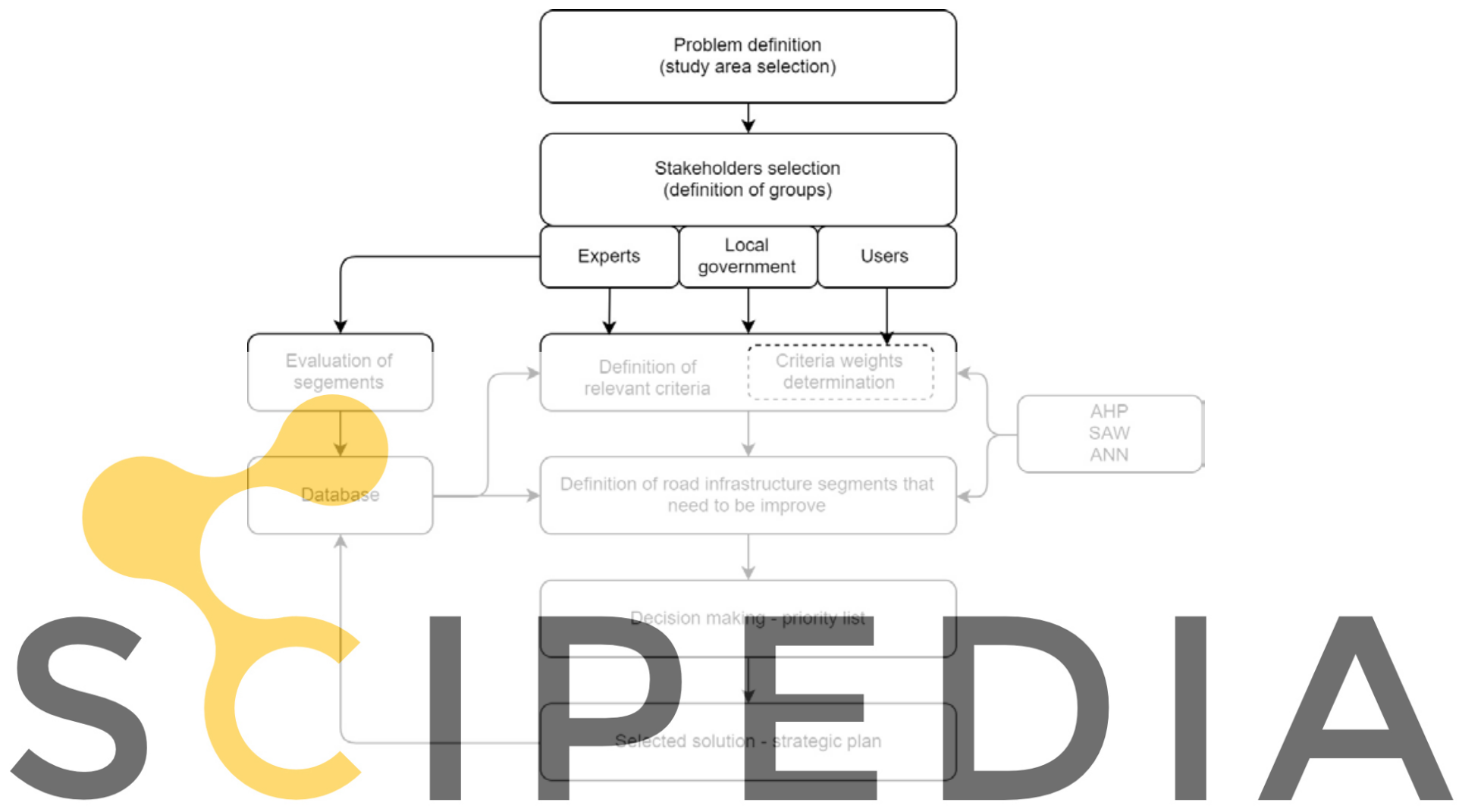

Figure 1. Decision support to road infrastructure segments improvement

Register for free at https//www.scipedia.com to download the version without the watermark 3 Road Infirastructure Segments Improvement Planning

The city of Split is taken as a study area. It has a high concentration of public facilities and pedestrian flows. There were 236 identified infrastructure segments, divided into 10 types: street, street section, crossroad, garage, parking, bus station, bus terminal, petrol station, overpass and tunnel. To evaluate each of the elements 13 criteria are defined. Each group of stakeholders defined criteria in their field of expertise. These criteria are grouped in social, technical, economic and ecologic group, as is shown in Table 1. Three scenarios are created, one for each stakeholders' groups and each for each scenario criteria weights are determined using AHP method. Compromise scenario is calculated as average value of each criterion weight by each scenario. Using compromise scenario, opinions of all three groups are equally taken into account. 
Table 1. Criteria definition with weights and scenarios.

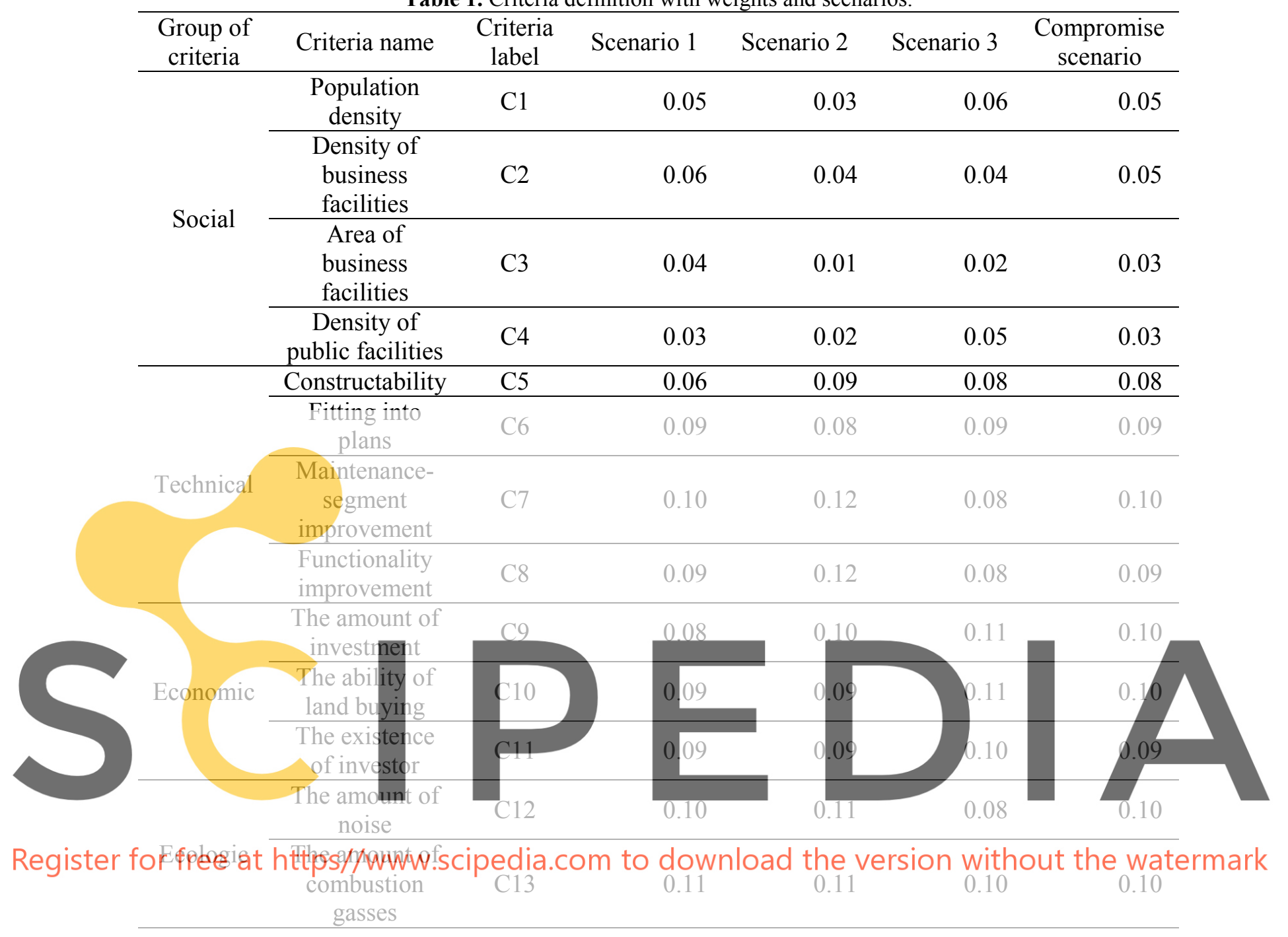

Criterion C7 (Maintenance - segment improvement) is divided into four subcriteria: level of service, safety, time period passed form the last renovation and stability. Using these four subcriteria and methodology of ANN, the unique Condition Assessment Value (CAV) is obtained. This value also presents an assessment of condition of segment.

\section{Results}

Using methodology of ANN, road-infrastructure segments in poor conditions are identified, by including four input variables and only one output variable. The four input variables are four criteria defined in previous section: level of service, safety, time period passed form the last renovation and stability. This ANN is trained by the back-propagation algorithm using the training set consisting of 200 cases, each case with four input variables (collected during the monitoring cycle), and 200 output variables, provided by experts' assessment. The output variable is CAV. Input values for 236 segments are collected during the second monitoring 
cycle. Applying ANN methodology, conditions of segments are obtained. However, only segments assessed as inadequate and poor were selected for further analysis. If the CAV is less then 1 , condition is classified as bad ( 0 -worst condition, 1-the best condition). Segments with CAV values are shown in Table 2 . There are 18 segments with poor condition, and the best one is segment $\mathrm{Sg} 13$ (crossroad), while the worst is $\mathrm{Sg} 8$ (street section).

Table 2. Road infrastructure segments with poor condition.

\begin{tabular}{|c|c|c|}
\hline Infrastructure segment & Label of segment & CAV \\
\hline Street section (Pojišanska1) & $\mathrm{Sg} 1$ & 0.458 \\
\hline Street section (Pojišanska 2) & $\mathrm{Sg} 2$ & 0.634 \\
\hline Crossroad (Pojišanska i Zvonimirova) & Sg3 & 0.556 \\
\hline Street (Put Stinica) & $\mathrm{Sg} 4$ & 0.543 \\
\hline Street section (Sukoišanska) & $\mathrm{Sg} 5$ & 0.687 \\
\hline $\begin{array}{c}\text { Crossroad (Meštrovićeva, Sustipanskog P. and } \\
\text { Ulica Dražanac) }\end{array}$ & $\operatorname{Sg} 6$ & 0.731 \\
\hline Crossroad (Spinčićeva, Zajčeva and Put Firula) & $\mathrm{Sg} 7$ & 0.476 \\
\hline Street section (Ulica slobode) & Sg8 & 0.437 \\
\hline Garage (Varoš 4) & Sg9 & 0.489 \\
\hline $\begin{array}{c}\text { Crossroad (Hercegovačka, Put suplava and Put } \\
\text { stinica) }\end{array}$ & $\operatorname{Sg} 10$ & 0.685 \\
\hline Crossroad (Sukoišanska and Starčevićeva) & Sg11 & 0.577 \\
\hline Street section (Domovinskog rata) & Sg12 & 0.496 \\
\hline Crossroad (Kavanjinova, Manc*erova) & Sg13 & 0.832 \\
\hline Garage (Spinut North 4) & Sg14 & 0.74 \\
\hline Bus station (Pojišanska 2) & Sg15 & 0.659 \\
\hline Garage (Lovret North 1) & Sg16 & 0.67 \\
\hline $\begin{array}{c}\text { Crossroad (Mažuranićevevo Š., Dom. rata and } \\
\text { Gundulićeva) }\end{array}$ & & 0.68 \\
\hline
\end{tabular}

Tabie 3 shows the ranking of the infrastructure segments. Criteria weights values are caiculate from the compromise scenario. These weight values are then used in the SAW method. Segments are evaluated by experts. Evaluations are normalized and transformed, and then SAW is included in further process. All of 13 criteria are used for evaluation of 18 infrastructure segments. Table 3 shows the ranking of 18 segments. The segment evaluation with higher score value means that the segment is considered as prior to improvement. In this case segment Sg10 (76.87) has the highest value, while the Sg8 (25.88) has the lowest. 
Table 3. Ranking of segments.

\begin{tabular}{cccccc}
\hline Segment label & Score & Rank position & Segment label & Score & Rank position \\
\hline $\mathrm{Sg} 1$ & 70.32 & 7. & $\mathrm{Sg} 10$ & 76.87 & 1. \\
\hline $\mathrm{Sg} 2$ & 72.75 & 4. & $\mathrm{Sg} 11$ & 54.12 & 11. \\
\hline $\mathrm{Sg} 3$ & 71.58 & 6. & $\mathrm{Sg} 12$ & 49.16 & 14. \\
\hline $\mathrm{Sg} 4$ & 44.35 & 15. & $\mathrm{Sg} 13$ & 38.67 & 17. \\
\hline $\mathrm{Sg} 5$ & 73.28 & 3. & $\mathrm{Sg} 14$ & 66.57 & 8. \\
\hline $\mathrm{Sg} 6$ & 58.21 & 10. & $\mathrm{Sg} 15$ & 53.41 & 12. \\
\hline $\mathrm{Sg} 7$ & 40.13 & 16. & $\mathrm{Sg} 16$ & 63.18 & 9. \\
\hline $\mathrm{Sg} 8$ & 25.88 & 18. & $\mathrm{Sg} 17$ & 72.45 & 5. \\
\hline $\mathrm{Sg} 9$ & 73.31 & 2. & $\mathrm{Sg} 18$ & 49.82 & 13. \\
\hline
\end{tabular}

With proposed model of decision support, ranking list for the priority of improvement of infrastructure segments is obtained as is shown in Table 3. Then local-government representatives selected the most appropriate solution, according to the results of the ranking and present policies. The selected solution must be in consent with financials available in the budget of city of Split. Finally, eight top-ranked segments are included in the maintenance plan, in the next investment period.

\section{Conclusions}
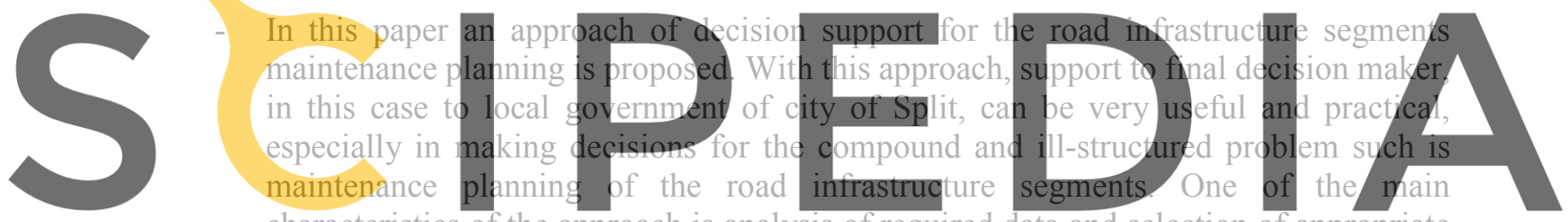

characteristics of the approach is analysis of required data and selection of appropriate

Register for free ath. htt.j.s//www. scipedia.com to downhoad the version without the watermark segments. Relevant stakeholders are identified and gathered together to determined criteria that are used for segments evaluation. Stakeholders were divided into three groups: local government, experts, and users, and were directly involved in the decisionmaking process, expressing their opinions through criteria weights, using AHP and SAW method.

- This approach is a combination of multicriteria analysis and ANN. Monitoring the infrastructure segments using relevant criteria such are level of service, safety, time period passed form the last renovation and stability, data were collected that were further introduced into the ANN methodology. This way, condition evaluations of infrastructure segments are obtained as values of CAV. Involving ANN methodology as a knowledge-based system, substitution of experts can be achieved.

- The presented approach of decision support is an adequate tool for decision makers in the field of the improvement of maintenance planning of road-infrastructure segments.

\section{Acknowledgements}

This research is partially supported through project KK.01.1.1.02.0027, a project co-financed by the Croatian 
Government and the European Union through the European Regional Development Fund-the Competitiveness and Cohesion Operational Programme.

\section{ORCID}

Nikša Jajac: https://orcid.org/0000-0003-2218-6507

\section{References}

Bielli, M. (1992). A DSS approach to urban traffic management, European Journal of Operational Research, 61(12), 106-113.

Deluka-Tibljaš, A., Karleuša, B., and Dragičević, N.(2013). Review of multicriteria-analysis methods application in decision making about transport infrastructure. Građevinar, 65(7), 619-631.

Dunkel, J., Fernandez, A., and Ortiz, R. et al. (2011). Event-Driven Architecture for Decision Support in Traffic Management Systems. Expert systems with applications , 38(6), 6530-6539.

Guisseppi, A., and Forgionne, G.A. (2002). Selecting rail grade crossing investments with a decision supportsystem. Information Sciences, 144(1-4), 75-90.

He, S., Song, R., and Chaudhry, S.S. (2014). Service-oriented intelligent group decision support system:Application in transportation management. Information Systems Frontiers, 16 (5), 939-951.

Hwang, C.-L., and Yoon, K. (1981). Multiple Attribute Decision Making: Methods and Applications - A State-of the-Art Survey. Springer-Verlag, New York.

Jajac, N. (2010). Modeling of the decision support systems for urban road infrastructure development and maintenance. Dissertation, University of Split, Faculty of Economics, Split, Croatia.

Jajac, N., Knezić, S., and Marović, I. (2009). Decision support system to urban infrastructure maintenance management. Organization, Technology and Management in Construction - An International Journal, 1(2), 72 79.

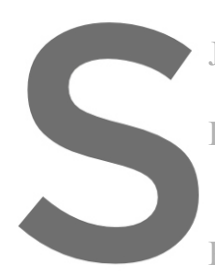

Jajac, N., Marovic, I., and B parking facilities. Election

Leclerc, G., Hmiya, S., Aïme system (IDSS) for an Systemics, Cybernetics an Baucic, M. (2014). Decicis
nic journal of the Faculty o
eur, E., Quintero, A., Pierre
uban infrastructure comp
W.P. (2008). The U.S. Fe
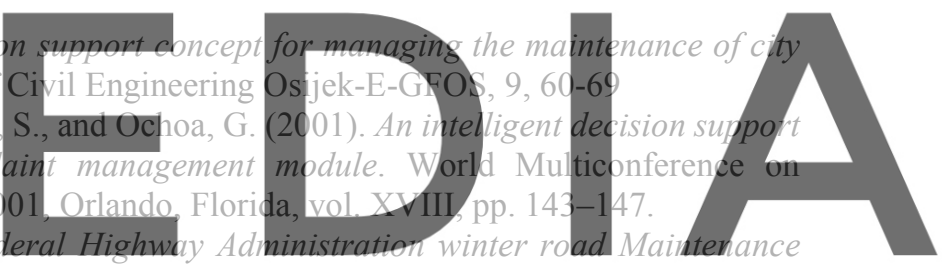
Decision Support System (MDSS): Recent enhancements \& refinements. Sirwec, Prague, 14-16 May, 29: 1-12.

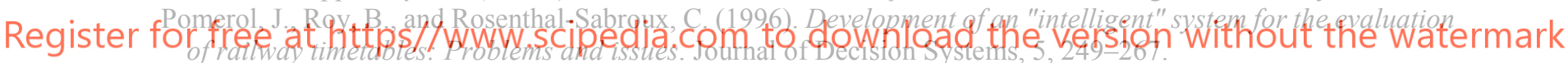

Quintero, A., Konaré, D., and Pierre, S. (2005). Prototyping an intelligent decision support system for improving urban infrastructures management. European Journal of Operational Research, 162(3), 654-672.

Saaty, T.L.: Decision Making for Leaders, The Analytic Hierarchy Process for Decisions in a Complex World, Wadsworth, Belmont, 1982.

Sayers, T.M., Jessop, A.T., and Hills, P.J. (2003). Multi-criteria evaluation of transport options-flexible, transparent and user-friendly?, Transport Policy, 10(2), 95-105.

Shelton, J., and Medina, M. (2010). Integrated multiple-criteria decision making method to prioritizetransportation projects. Transportation Research Record: Journal of the Transportation Research Board, 2174,51-57.

Turban, E., and Aronson, J.E. (1995). Decision Support Systems and Intelligent Systems. 5th edition, Simon and Schuster Company, Upper Saddle River, NJ.

Zavadskas, E.K., Liias, R., and Turskis, Z. (2008). Multi-attribute decision-making methods for assessment of quality in bridges and road construction: state-of-the-art surveys. The Baltic journal of road and bridgeengineering, 3(3), 152-160.

Zhou, G., Wang, L., Wang,D., and Reichle, S. (2010). Integration of GIS and Data Mining Technology to Enhance the Pavement Management Decision Making. Journal of Transportation Engineering, 136(4), 136:332-341. 